\title{
FAKTOR-FAKTOR YANG MEMPENGARUHI PERILAKU IMPULSE BUYING KONSUMEN PRODUK ORIFLAME DI KOTA LANGSA
}

\author{
Meutia Dewi $^{{ }^{* *} \text {, Melly Kurniawan }}{ }^{1)}$ \\ ${ }^{1)}$ Fakultas Ekonomi, Universitas Samudra, Langsa \\ Penulis Korespondensi: meutiadewi@unsam.ac.id ${ }^{1 *}$
}

\begin{abstract}
The purpose of this study was to determine the effect of personal selling, price discount, and bonus packs on the impulse buying of Oriflame consumers in Langsa City. The sample in this study amounted to 97 respondents. The sampling technique used in this study is non-probability sampling. The data analysis method used in this research is multiple linear regression analysis, $t$ test, $F$ test and coefficient of determination. The regression equation in this study is: $Y=4.239+0.300 \times 1+0.124 \times 2+0.339 \times 3$. The constant 4.239 shows the value of impulse buying if personal selling, price discounts and bonus packs are fixed. The coefficients of personal selling variables, price discounts and bonus packs have a positive effect on impulse buying of consumers of Oriflame products in Langsa City. Based on partial and simultaneous hypothesis testing, personal selling, price discount and bonus pack variables have a significant effect on impulse buying. The value of the coefficient of determination of 0.604 or $60.4 \%$ can be concluded that impulse buying can be explained by personal selling, price discounts, and bonus packs, while the remaining $39.6 \%$ can be explained by factors not included in the study.
\end{abstract}

Keyword: Personal Selling, Price Discount, Bonus Packs, Impulse Buying

\section{Article Information:}

Received Date: 10 Oktober 2021

Revised Date: 14 Oktober 2021

Accepted Date: 24 Oktober 2021 


\section{PENDAHULUAN}

Personal selling salah satu topik yang paling menarik dibahas, salah satu alasannya adalah karena dalam prosesnya selalu melibatkan hubungan personal selling (personal relationship) antara sang penjual, sales person, dan sang pembeli. Penjual dan pembeli sering dihadapkan dengan situasi harus bertemu dan bertatap muka. Ardianto (2015) menyatakan bahwa penjualan tatap muka merupakan salah satu variabel di dalam marketing mix yang dilakukan secara lisan kepada satu atau lebih calon pembeli yang dilakukan dengan tujuan menciptakan terjadinya transaksi. Untuk masa sekarang personal selling sudah bisa diterapkan dengan berbagai media sosial seperti facebook, instagram, whatshapp, dan lain-lain. Dengan penggunaan media ini para penjual produk lebih mendapatkan kemudahan untuk menawarkan produk-produknya. Dari sisi waktu juga menjadi efisien dan lebih tepat sasaran pada konsumen yang akan dituju. Dari sisi harga pun produk-produk yang ditawarkan relatif murah dibandingkan dengan produk-produk lainnya yang dijual secara konvensional.

Menurut Kotler dan Keller (2012), price discount merupakan penghematan yang ditawarkan pada konsumen dari harga normal akan suatu produk, yang tertera dilabel atau kemasan produk tersebut. Potongan harga menjadi daya tarik utama untuk menarik minat masyarakat membeli suatu barang. Salah satu bentuk promosi ini merupakan bentuk promosi yang paling disukai oleh konsumen. Seseorang yang ketika itu melihat adanya potongan harga akan cenderung tertarik untuk melihat dan membeli barang tersebut.

Kurniawan dan Yohanes (2013) mengemukakan bahwa impulse buying dapat diartikan sebagai tindakan pembelian yang dilakukan secara mendadak dan tanpa melalui proses perencanaan sebelumnya. Hal ini bisa terjadi pada produk-produk low involvement yang selalu tidak memerlukan pertimbangan yang rumit untuk membelinya. Produk low involvement adalah produk yang dibeli secara rutin dengan pemikiran dan usaha yang minumum, karena bukan merupakan suatu hal yang vital dan juga tidak memberikan pengaruh yamg besar terhadap gaya hidup konsumen.

Penelitian mengenai faktor-faktor yang mempengaruhi impulse buying telah banyak dilakukan, seperti Pradhana dan Martini (2018) yang melakukan penelitian dengan judul "Pengaruh Personal Selling, Price Discount, dan Bonus Pack Program terhadap Perilaku Impulse Buying Konsumen Produk Oriflame pada PT Orindo Alam Ayu di Kota Denpasar". Hasil penelitian menunjukkan bahwa bahwa personal selling, price discount dan bonus pack secara parsial dan simultan berpengaruh signifikan terhadap impulse buying.

Syazkia dan Yuliati (2018) juga melakukan penelitian dengan judul "Pengaruh Bonus Pack dan Price Discount terhadap Keputusan Impulse Buying pada Konsumen PT Lion Super Indo Gerai Antapani”. Hasil penelitian menunjukkan bahwa bonus pack dan price discount secara parsial dan simultan berpengaruh signifikan terhadap impulse buying.

Produk Oriflame di Kota Langsa sudah sangat dikenal yang memiliki berbagai kategori yaitu: Skin Care, Make-Up, Wellbeing, Fragrance, Men's Corner, dan Personal Care. Pembelian produk-produk Oriflame hanya bisa melalui member Oriflame saja. Dikarenakan Oriflame adalah perusahaan direct selling yang bergantung pada distributor yang berperan sebagai tenaga penjual di mana merupakan ujung tombak perusahaan dalam memasarkan dan menjual produknya dengan modal katalog online maupun offline.

Penelitian pendahuluan dilakukan melalui observasi pada konsumen produk Oriflame yang berada di Kota Langsa yang pernah membeli produk tersebut dan juga melalui whatsapp (WA) kepada konsumen Oriflame yang ada di Kota Langsa yang berjumlah 25 konsumen dengan cara mengajukan pertanyaan sesuai dengan indiktor personal selling, price discount dan bonus pack yang terdapat dalam penelitin ini. Maka hasil 
yang di dapat yaitu sebagai berikut: Personal selling yang dilakukan oleh member Oriflame kadang tidak seperti yang diharapkan oleh konsumen karena para member memiliki perbedaan pengetahuan dan kemampuan, sehingga melakukan dengan cara dan gaya yang berbeda dalam menyampaikan informasi serta penjelasan yag kurang konsisten terhadap kelebihan atau kekurangan produk yang akan menimbulkan keraguan konsumen untuk membelinya. Price discount yang diberikan memberi anggapan bagi konsumen bahwa harga diskon yang ditawarkan mengalami perubahan setiap bulannya. Hal tersebut membuat konsumen tidak jadi membeli produk yang di inginkannya.

Bonus pack yang diberikan Oriflame sering harus memenuhi syarat yang diberikan terlebih dahulu yang membuat konsumen merasa kecewa karena tidak bisa memenuhi syarat yang diberikan. Walau kadang tawaran hadiah yang diberikan sangat bagus dan membuat konsumen ingin membelinya. Waktu pemberian bonus pack secara tiba-tiba membuat konsumen tidak siap untuk mendapatkan bonus pack karena memiliki syarat yang harus di penuhi bagi konsumen.

Adapun tujuan yang ingin dicapai dalam penelitian ini adalah: (1) Untuk mengetahui pengaruh personal selling, price discount, dan bonus pack program secara parsial terhadap perilaku impulse buying konsumen produk Oriflame di Kota Langsa, (2) Untuk mengetahui pengaruh personal selling, price discount, dan bonus pack program secara simultan terhadap perilaku impulse buying konsumen Produk Oriflame di Kota Langsa.

Berdasarkan uraian latar belakang, maka hipotesis dalam penelitian ini adalah: (1) Personal selling, price discount, dan bonus pack program berpengaruh signifikan secara parsial terhadap perilaku impulse buying konsumen produk Oriflame di Kota Langsa, (2) Personal selling, price discount, dan bonus pack program berpengaruh signifikan secara simultan terhadap Perilaku impulse buying konsumen produk Oriflame di Kota Langsa.

\section{TINJAUAN PUSTAKA Personal Selling}

Mowen \& Minor (2010) mendefinisikan impulse buying adalah tindakan membeli yang dilakukan tanpa memiliki masalah sebelumnya atau maksud/niat membeli yang terbentuk sebelum memasuki toko. Hal senada juga diungkapkan oleh Schiffman \& Kanuk (2007) bahwa impulse buying merupakan keputusan yang emosional atau menurut desakan hati.

Kotler dan Keller (2012), menjelaskan tedapat enam langkah personal selling yaitu:

1. Mencari calon pelanggan (prospek) dan mengkualifikasinya. Langkah pertama dalam penjualan adalah mengidentifikasi pelanggan dan mengkualifikasi. Semakin banyak perusahaan yang bertanggung jawab untuk mencari dan mengkualifikasikan petunjuk sehingga wiraniaga dapat menggunakan waktu mereka yang tidak banyak untuk melakukan apa yang dapat mereka lakukan dengan baik.

2. Prapendekatan. Wiraniaga harus belajar sebanyak mungkin calon pembelinya. Wiraniaga harus menetapkan tujuan kunjungan, mengkualifikasi calon pelanggan, mengumpulkan informasi, melakukan penjualan segera.

3. Presentasi dan demonstrasi. Wiraniaga menyampaikan "kisah" produk kepada pembeli menggunakan pendekatan fitur, keunggulan (advantage), manfaat (benefit), dan nilai (value) (FABV). Fitur menggambarkan karakteristik fisik penawaran pasar, seperti kecepatan pemprosesan chip atau kapasitas memori. Keunggulan menjelaskan mengapa fitur itu memberikan keuntungan kepada pelanggan.

4. Mengatasi keberatan. Pelanggan biasanya mengajukan keberatan. Resistensi psikologis meliputi resistensi terhadap interferensi, preferensi terhadap sumber pasokan atau merek yang sekarang digunakan, apatis, tidak bersedia melupakan sesuatu, hubungan tidak menyenangkan diciptakan oleh wiraniaga. 
5. Penutupan. Tanda penutupan dari pembeli meliputi tindakan fisik, pernyataan atau komentar dan pertanyaan.

6. Tindak lanjut dan pemeliharaan. Tindak lanjut dan pemeliharaan diperlukan untuk memastikan kepuasan pelanggan dan terluangnya kerja sama. Segera setelah menutup penjualan, wiraniaga harus menyatukan semua data yang diperlukan tentang waktu pengiriman, syarat pembelian, dan masalah penting bagi pelanggan.

Akkas (2016:26) mengemukana terdapat tiga indikator dalam mengukur personal selling yaitu:

1. Tenaga penjual

Tenaga penjualan atau sering disebut wiraniaga (sales) adalah seorang individu yang mewakili sebuah perusahaan kepada pelanggan dengan melakukan satu atau lebih aktivitas mulai dari mencari pelanggan, berkomunikasi, menjual, melayani mengumpulkan informasi dan membangun hubungan. Istilah wiraniaga (sales) meliputi posisi yang luas jangkauannya.

2. Presentasi penjualan

Yaitu proses personal selling dimana wiraniaga menceritakan riwayat produk kepada pembeli, wiraniaga mengedukasi tentang segala produk bagi pelanggan.

3. Sampel

Sampel merupakan contoh produk-produk yang akan dijelaskan kepada calon pembeli agar lebih mudah memahami dan mendapatkan kepuaskan pembeli ketika sudah membeli sesuai dengan yang dijelaskan sejak awal.

\section{Price Discount}

Menurut Tjiptono (2008), price discount merupakan potongan harga yang diberikan oleh penjual kepada pembeli sebagai penghargaan atas aktivitas tertentu dari pembeli yang menyenangkan bagi penjual.

Wahyudi (2017) mengemukakan bahwa indikator dari price discount adalah:
1. Frekuensi diskon

Frekuensi diskon mengacu pada seberapa sering pemasar dalam suatu gerai ritel melakukan potongan harga terhadap produk yang ditawarkannya.

2. Besaran diskon

Besaran diskon merupakan seberapa besar diskon yang ditawarkan oleh pemasar terhadap produk yang ditawarkan kepada konsumennya, yang dapat dilihat dari persentasi misalnya $30 \%, 50 \%$ dll.

3. Waktu pembelian diskon

Waktu pemberian diskon merujuk pada kapan saja waktu yang dipilih pemasar utuk melakukan potongan harga produk yang ditawarkan kepada para konsumen.

\section{Bonus Pack}

Clow dan Baack mendefinisikan ketika sejumlah item tambahan (ekstra) ditempatkan dalam paket produk khusus, ini adalah bonus pack (paket bonus).

Bonus paket tentunya akan memberikan manfaat kepada perusahaan dan konsumen. Bagi seorang konsumen akan mengusahakan kepuasan terhadap produk yang dibelinya. Kepuasan ini bukan hanya terletak pada kualitas produk yang ada, melainkan juga tata cara pembayaran. Misalnya yakni paket bonus terhadap pembelian produk tertentu sesuai dengan ketentuan dan syarat yang ada.

Belch dan Belch mengembangkan jika variabel bonus pack dapat diukur melalui tiga indikator yang meliputi:

1. Memberikan penawaran dengan manfaat ekstra.

Perusahaan melakukan diskon melalui barang-barang tertentu dengan menambahkan bonus barang yang memiliki banyak manfaat bagi konsumen.

2. Strategi bertahan terhadap promosi produk baru dari pesaing.

Meningkatkan kualitas produk, menambah ciri-ciri atau fitur-fitur produk, serta memperbaiki modelnya. 
3. Menghasilkan pesanan penjualan yang lebih besar.

Perusahaan melakukan diskon besar besaran untuk menarik konsumen membeli produk dengan jumlah yang lebih banyak dan biasanya jika konsumen menyukai barang yang sama mereka akan memesan secara khusus barang dengan harga miring.

\section{Impulse Buying}

Impulse Buying didefinisikan sebagai tindakan membeli yang sebelumnya tidak diakui secara sadar sebagai hasil dari suatu pertimbangan atau niat membeli yang terbentuk sebelum memasuki toko (Kwan, 2016).

Indikator impulse buying dikemukakan oleh Bayley dan Nancarrow (1998) yang terdiri dari:

1. Pembelian spontan

Merupakan keadaan di mana pelanggan sering membeli sesuatu tanpa direncanakan terlebih dahulu

2. Pembelian tanpa berpikir akibat

Merupakan keadaan di mana pelanggan sering melakukan pembelian tanpa memikirkan terlebih dahulu mengenai akibat dari pembelian yang dilakukan tanpa memikirkan terlebih dahulu mengenai akibat dari pembelian yang dilakukan.

3. Pembelian terburu-buru

Merupakan keadaan di mana pelanggan seringkali merasa bahwa terlalu terburuburu dalam membeli sesuatu.

4. Pembelian dipengaruhi oleh emosional Adalah penilaian pelanggan di mana pelanggan melakukan berbelanja dipengaruh oleh keadaan emosional.

\section{METODE PENELITIAN}

Ruang lingkup pada penelitian ini adalah manajemen pemasaran yang berfokus pada personal selling, price discount, bonus pack program sebagai variabel bebas dan impulse buying sebagai variabel terikat. Lokasi penelitian dilakukan di Kota Langsa mulai bulan Januari 2020 sampai Juni 2020.
Populasi dalam penelitian ini adalah seluruh konsumen Oriflame yang ada di Kota Langsa dengan jumlah populasi yang tidak diketahui secara pasti, dan identitasnya disesuaikan dengan kebutuhan penelitian. Penentuan jumlah sampel menggunakan rumus Unknown Population dikemukakan oleh Sarwono (2011), yaitu:

$$
n=\frac{\left(Z^{2}\right)}{4 \mu^{2}}
$$

Keterangan:

$$
\mathrm{n} \quad=\text { Jumlah sampel }
$$

$\mathrm{Z}=$ Tingkat kepercayaan $95 \%$ maka $\mathrm{Z}$ $=1,96$

$\mu \quad=$ Tingkat kesalahan (ditentukan 10\%)

Peneliti memperoleh sampel yang besar dan nilai $\mathrm{p}$ belum diketahui, maka dapat digunakan $\alpha=5 \%$ atau 0,5 dengan demikian jumlah sampel yang mewakili adalah:

$$
n=\frac{1,96^{2}}{4(0,1)^{2}}=96,7 \quad \text { dibulatkan } 97
$$

responden.

Jumlah sampel dalam penelitian ini berjumlah 97 responden. Teknik sampling atau teknik penarikan sampel yang digunakan dalam penelitian ini adalah non probability sampling dengan menggunakan teknik accidental sampling, yaitu teknik penentuan sampel berdasarkan kebetulan, artinya siapa saja yang secara kebetulan bertemu dengan peneliti, bila dipandang cocok sebagai sumber data (Sugiyono, 2017:81).

Metode pengumpulan data yang digunakan adalah:

1. Penelitian Lapangan

a. Observasi

Observasi dalam penelitian ini dilakukan untuk mengamati konsumen yang pernah membeli produk Oriflame di Kota Langsa.

b. Wawancara

Wawancara pada penelitian ini dilakukan pada konsumen Oriflame di Kota Langsa yang pernah membeli produk Oriflame.

c. Kuesioner

Kuesioner disebarkan kepada konsumen yang pernah membeli produk Oriflame di Kota Langsa untuk menjawab pertanyaan 
dengan penilaian skala likert yang diberikan skor 1-5 dengan kriteria sebagai berikut:

Sangat Tidak Setuju

bernilai 1

Tidak Setuju

bernilai 2

Kurang Setuju

bernilai 3

Setuju

bernilai 4

Sangat Setuju

bernilai 5

2. Penelitian Kepustakaan

Pengumpulan data sekunder pada penelitian ini diperoleh dari buku-buku referensi, jurnal, artikel yang dianggap menjadi referensi pendukung berupa teori-teori dan informasi yang berhubungan dengan penelitian ini.

Penelitian ini dilakukan dengan empat tahapan analisis data yaitu:

1. Uji Validitas dan Reliabilitas

a. Uji Validitas

Uji validitas digunakan untuk mengukur sah atau valid tidaknya suatu kuesioner (Ghojali, 2011). Menurut Sinulingga (2013) untuk mengetahuai item pertanyaan mana yang tidak memiliki validitas yang memadai maka batas minimum $r$ ialah 0,30 bila dalam kuesioner ada item pertanyaan yang mendapat koefisien korelasi < 0,30 maka pertanyaan tersebut diperbaiki atau tidak jarang pula item pertanyaan tersebut di drop dari kuesioner.

b. Uji Reliabilitas

Uji reabilitas merupakan pengujian yang menunjukkan sejauh mana stabilitas dan konsistensi dari alat ukur yang digunakan. Menurut Sunyoto (2011), bukti kuesioner dikatakan reliabel (layak) jika Cronbach Alpha> 0,6 dan dikatakan tidak reliabel jika Cronbach Alpha < 0,6.

2. Analisis Regresi Linear Berganda
Persamaan regresi linier berganda pada penelitian ini di kemukakan oleh Sugiyono (2008):

$\mathrm{Y}=\mathrm{a}+\mathrm{b}_{1} \mathrm{X}_{1}+\mathrm{b}_{2} \mathrm{X} 2+\ldots \ldots+\mathrm{b}_{\mathrm{n}} \mathrm{X}_{\mathrm{n}}$

Keterangan:

$\mathrm{Y}=$ Variabel terikat

$\mathrm{X}_{1}, \mathrm{X}_{2}, \mathrm{X}_{3} \quad=$ Variabel bebas

$\mathrm{a}=$ Konstanta

$\mathrm{b}_{1}, \mathrm{~b}_{2} \quad=$ Koefisien regresi yang akan dihitung $\mathrm{X}_{1}, \mathrm{X}_{2}$

Kemudian untuk kebutuhan penelitian ini rumus diformulasikan sebagai berikut :

$$
\mathrm{Y}=\mathrm{a}+\mathrm{b}_{1} \mathrm{X}_{1}+\mathrm{b}_{2} \mathrm{X}_{2}+\mathrm{b}_{3} \mathrm{X}_{3}+\mathrm{b}_{4} \mathrm{X}_{4}
$$

Keterangan :

$\mathrm{Y} \quad=$ impulse buying

A $\quad$ konstanta

$\mathrm{b}_{1} \quad=$ koefisien regresi Personal Selling

$\mathrm{b}_{2} \quad=$ koefisien regresi Price Discount

$\mathrm{b}_{3} \quad=$ koefisien regresi Bonus Pack

$\mathrm{X}_{1} \quad=$ variable Personal Selling

$\mathrm{X}_{2} \quad=$ variabel Price Discount

$\mathrm{X}_{3} \quad=$ variabel Bonus Pack

3. Uji Hipotesis

a. Uji Parsial (Uji t)

Uji t digunakan untuk mengetahuai tingkat signifikansi pengaruhnya variabel-variabel bebas terhadap variabel terikat. Hipotesis yang digunakan dalam penelitian ini adalah:

1) $H_{0}: \beta_{1}=0$, terdapat pengaruh yang tidak signifikan dari personal selling terhadap impulse buying pada konsumen produk Oriflame di Kota Langsa.

$\mathrm{H}_{0}: \beta_{2}=0$, terdapat pengaruh yang tidak signifikan dari price discount terhadap impulse buying pada konsumen produk Oriflame di Kota Langsa.

$\mathrm{H}_{0}: \beta_{3}=0$, terdapat pengaruh yang tidak signifikan dari bonus pack terhadap impulse buying pada konsumen produk Oriflame di Kota Langsa.

2) $\mathrm{H}_{\mathrm{a}}: \beta_{1} \neq 0$, terdapat pengaruh yang signifikan dari personal selling 
terhadap impulse buying pada konsumen produk Oriflame di Kota Langsa.

$H_{a}: \beta_{2} \neq 0$, terdapat pengaruh yang signifikan dari price discount terhadap impulse buying pada konsumen produk Oriflame di Kota Langsa.

$\mathrm{H}_{\mathrm{a}}: \beta_{3} \neq 0$, terdapat pengaruh yang signifikan dari bonus pack terhadap impulse buying terhadap konsumen produk Oriflame di Kota Langsa.

3) Level of signifikansi yaitu sebesar 5\%

4) Kriteria pengujian
a) Jika nilai $t$ sig. $>\alpha=0,05$, maka hipotesis $\mathrm{H}_{0}$ diterima dan $\mathrm{H}_{\alpha}$ ditolak
b) Jika nilai t sig. $<\alpha=0,05$, maka hipotesis $\mathrm{H}_{0}$ ditolak dan $\mathrm{H}_{\alpha}$ diterima.

b. Uji Simultan (Uji f)

Uji $F$ adalah alat untuk menguji signifikansi apakah variabel indenpenden (personal selling, price discount, dan bonus pack) secara serentak berpengaruh terhadap variabel dependen (impulse buying).

1) $\mathrm{H}_{0}: \beta_{\mathrm{i}}=0$, terdapat pengaruh yang tidak signifikan secara simultan personal selling. Price discount, dan bonus pack terhadap impulse buying terhadap konsumen produk Oriflame di Kota Langsa.

2) $\mathrm{H}_{\mathrm{a}}: \beta_{\mathrm{i}} \neq 0$, terdapat pengaruh yang signifikan secara simultan personal selling, price discount, dan bonus pack terhadap impulse buying pada konsumen prouk Oriflame di Kota Langsa.

3) Level of signifikansi yaitu sebesar 5\%

4) Kriteria pengujian
a) Jika nilai t sig. $>\alpha=0,05$, maka hipotesis $\mathrm{H}_{0}$ diterima dan $\mathrm{H} \alpha$ ditolak
b) Jika nilai t sig. $<\alpha=0,05$, maka hipotesis $\mathrm{H}_{0}$ ditolak dan $\mathrm{H} \alpha$ diterima.

4. Uji Koefisien Determinasi (Adjusted $\mathrm{R}^{2}$ )
Koefisien determinasi digunakan untuk menghitung besarnya peranan atau pengaruh variabel bebas (X) terhadap variabel terikat (Y). Nilai $\mathrm{R}^{2}$ menunjukkan bahwa variasi variabel terikat dapat dijelaskan oleh variasi variabel bebas. Nilai $\mathrm{R}^{2}$ mendekati nol (0), maka variasi dari variabel terikat tidak dapat dijelaskan oleh variabel bebas. Sebaliknya jika mendekati 1 (satu) berarti variabel bebas memberikan hampir semua informasi yang dibutuhkan untuk memprediksi variabel terikat (Arikunto, 2010)

\section{HASIL DAN PEMBAHASAN}

Proses uji instrumen dilakukan dengan menyebarkan kuesioner kepada 30 orang responden. Para responden diminta menjawab sekaligus memberi masukan jika ada item pertanyaan yang sebenarnya bisa disederhanakan. Hasil penyebaran kepada 30 orang dianalisis dengan menggunakan uji validitas dan reliabilitas.

Hasil uji validitas pada variabel personal selling, price discount, dan bonus pack serta impulse buying dapat diihat pada tabel 1:

Tabel 1. Hasil Uji Validitas

\begin{tabular}{|l|c|c|c|c|}
\hline Variabel & Item & $\begin{array}{c}\text { Korelasi } \\
\text { Pearson }\end{array}$ & $\begin{array}{c}\mathbf{r} \\
\text { tabel }\end{array}$ & $\begin{array}{c}\text { Hasil } \\
\text { Uji }\end{array}$ \\
\hline $\begin{array}{l}\text { Personal } \\
\text { selling } \\
\text { (X1) }\end{array}$ & $\mathrm{X}_{1.1}$ & 0,505 & 0,361 & Valid \\
\hline & $\mathrm{X}_{1.2}$ & 0,658 & 0,361 & Valid \\
\hline & $\mathrm{X}_{1.3}$ & 0,732 & 0,361 & Valid \\
\hline & $\mathrm{X}_{1.4}$ & 0,544 & 0,361 & Valid \\
\hline & $\mathrm{X}_{1.5}$ & 0,608 & 0,361 & Valid \\
\hline & $\mathrm{X}_{1.6}$ & 0,729 & 0,361 & Valid \\
\hline $\begin{array}{l}\text { Price } \\
\text { DiScount } \\
\text { (X) })\end{array}$ & $\mathrm{X}_{2.1}$ & 0,659 & 0,361 & Valid \\
\hline & $\mathrm{X}_{2.2}$ & 0,789 & 0,361 & Valid \\
\hline & $\mathrm{X}_{2.3}$ & 0,774 & 0,361 & Valid \\
\hline & $\mathrm{X}_{2.4}$ & 0,774 & 0,361 & Valid \\
\hline & $\mathrm{X}_{2.5}$ & 0,839 & 0,361 & Valid \\
\hline & $\mathrm{X}_{2.6}$ & 0,611 & 0,361 & Valid \\
\hline
\end{tabular}




\begin{tabular}{|l|c|c|c|c|}
\hline $\begin{array}{l}\text { Bonus } \\
\text { Pack (X3) }\end{array}$ & $\mathrm{X}_{3.1}$ & 0,591 & 0,361 & Valid \\
\hline & $\mathrm{X}_{3.2}$ & 0,608 & 0,361 & Valid \\
\hline & $\mathrm{X}_{3.3}$ & 0,623 & 0,361 & Valid \\
\hline & $\mathrm{X}_{3.4}$ & 0,735 & 0,361 & Valid \\
\hline & $\mathrm{X}_{3.5}$ & 0,587 & 0,361 & Valid \\
\hline $\begin{array}{l}\text { Impulse } \\
\text { Buying }\end{array}$ & $\mathrm{Y}_{1}$ & 0,501 & 0,361 & Valid \\
\hline & $\mathrm{Y}_{2}$ & 0,765 & 0,361 & Valid \\
\hline & $\mathrm{Y}_{3}$ & 0,767 & 0,361 & Valid \\
\hline & $\mathrm{Y}_{4}$ & 0,765 & 0,361 & Valid \\
\hline & $\mathrm{Y}_{5}$ & 0,837 & 0,361 & Valid \\
\hline & $\mathrm{Y}_{6}$ & 0,809 & 0,361 & Valid \\
\hline
\end{tabular}

Sumber: data primer (diolah, 2020)

Berdasarkan tabel 1 diketahui bahwa hasil dari uji validitas pada variabel personal selling dengan enam item pertanyaan, price discount dengan enam item pertanyaan, bonus pack dengan lima item pertanyaan serta impulse buying dengan enam pertanyaan. Hasil uji dengan membandingkan nilai $r$ hitung dengan $r$ tabel. Nilai $r$ tabel yang yang didapat dengan melihat tabel $r$ statiska 0,361. Dengan kriteria valid > 0,361 dan melihat nilai semua $r$ hitung berada diatas 0,361 , maka semua pertanyaan pada kuesioner dinyatakan valid.

Hasil uji reliabilitas diukur dengan menggunakan nilai cronbach Alpha 0,6, dan dapat dinyatakan bahwa item pertanyaan semakin reliabel bila berada di atas 0,6. Hasil uji reliabilitas dapat dilihat pada tabel 2 berikut ini:

Tabel 2. Hasil Uji Reliabilitas

\begin{tabular}{|c|c|c|c|}
\hline Item & $\begin{array}{c}\text { Cronbach's } \\
\text { Alpha }\end{array}$ & r tabel & Hasil Uji \\
\hline $\begin{array}{c}\text { Personal } \\
\text { Selling }\end{array}$ & 0,686 & 0,6 & Reliabel \\
\hline $\begin{array}{c}\text { Price } \\
\text { Discount }\end{array}$ & 0,826 & 0,6 & Reliabel \\
\hline $\begin{array}{c}\text { Bonus } \\
\text { Pack }\end{array}$ & 0,844 & 0,6 & Reliabel \\
\hline $\begin{array}{c}\text { Impulse } \\
\text { Buying }\end{array}$ & 0,840 & 0,6 & Reliabel \\
\hline
\end{tabular}

Sumber: Data Primer (diolah,2020)
Berdasarkan hasil uji reliabilitas yang dapat dilihat pada tabel 2 di atas maka dapat disimpulkan bahwa seluruh variabel yang digunakan dalam penelitian ini adalah reliabel, karena nilai cronbach's alpha di atas 0,60.

Dalam mengetahui pengaruh variabel bebas (Personal Selling, Price Dicount, Bonus Pack) terhadap variabel terikat (Impulse buying) menggunakan analisis regresi linier berganda yang diolah melalui program SPSS Versi 18.0, sebagaimana ditunjukkan pada tabel 3. Dari hasil tersebut dapat ditulis persamaan regresi sebagai berikut:

$\mathrm{Y}=4,239+0,300 \mathrm{X}_{1}+0,124 \mathrm{X}_{2}+0,339 \mathrm{X}_{3}$ Persamaan regresi linier berganda tersebut dapat dijelaskan sebagai berikut:

1. Konstanta sebesar 4,239 menunjukkan nilai impulse buying apabila Personal Selling, Price Discount, Bonus Pack bernilai tetap.

2. Variabel Personal Selling menunjukkan pengaruh positif dengan impulse buying sebesar 0,300. Dengan kata lain, apabila personal selling nilainya bertambah satu satuan maka impulse buying akan meningkat sebesr 0,300 satuan dengan asumsi variabel personal selling, price discount, dan bonus pack bernilai tetap.

3. Variabel Price Discount menunjukkan pengaruh yang positif dengan impulse buying sebesar 0,124. Dengan kata lain, apabila price discount nilainya bertambah satu satuan maka impulse buying akan meningkatkan sebesar 0,124 satuan dengan asumsi variabel personal selling, price discount, bonus pack bernilai tetap.

4. Variabel bonus pack menunjukan pengaruh yang positif dengan impulse buying sebesar 0,339 . Dengan kata lain, apabila bonus pack nilainya bertambah satu satuan maka impulse buying akan meningkat sebesar 0,339 satuan dengan asumsi variabel personal selling, price discount, bonus pack bernilai tetap. 
Tabel 3. Coefficients ${ }^{\mathrm{a}}$

\begin{tabular}{|c|c|c|c|c|c|c|}
\hline \multirow{2}{*}{\multicolumn{2}{|c|}{ Model }} & \multicolumn{2}{|c|}{ Unstandardized Coefficients } & \multirow{2}{*}{$\begin{array}{c}\begin{array}{c}\text { Standardized } \\
\text { Coefficients }\end{array} \\
\text { Beta }\end{array}$} & \multirow[b]{2}{*}{$\mathrm{t}$} & \multirow[b]{2}{*}{ Sig. } \\
\hline & & B & Std. Error & & & \\
\hline \multirow[t]{4}{*}{1} & (Constant) & 4.239 & 1.196 & & 3.545 & .001 \\
\hline & Personal Selling & .300 & .064 & .391 & 4.658 & .000 \\
\hline & Price Discount & .124 & .052 & .188 & 2.400 & .018 \\
\hline & Bonus Pack & .339 & .074 & .361 & 4.562 & .000 \\
\hline
\end{tabular}

a. Dependent Variable: Impulse Buying

Sumber: Data Primer, diolah (2020)

Tabel 4. Model Summary

\begin{tabular}{|l|r|r|r|r|}
\hline Model & \multicolumn{1}{|c|}{$\mathrm{R}$} & R Square & Adjusted R Square & Std. Error of the Estimate \\
\hline 1 & $.785^{\mathrm{a}}$ & .617 & .604 & 2.196 \\
\hline
\end{tabular}

a. Predictors: (Constant), Bonus Pack, Price Discount, Personal Selling

Sumber: Data Primer, diolah (2020)

Berdasarkan tabel 4 terlihat nilai adjusted $\mathrm{R}$ square sebesar 0,604 . Hal ini berarti variabel Personal Selling, Price Discount, Bonus Pack mempengaruhi Impulse Buying Konsumen Produk Oriflame di Kota Langsa sebesar 60,4\% sementara sisanya $39,6 \%$ dipengaruhi oleh variabel lain yang tidak diteliti dalam peneitian ini seperti kualitas produk, harga dan lain sebagainya.

Pembuktian hipotesis pada penelitian ini menggunakan uji $\mathrm{t}$ dan uji $\mathrm{F}$ serta koefisien determinasi $\left(\mathrm{R}^{2}\right)$ :

\section{Uji t (Uji signifikansi parsial)}

Uji t yaitu suatu uji untuk mengetahui signifikansi pengaruh variabel bebas (Personal Selling, Price Discount, Bonus Pack) secara parsial ataupun individu menarangkan variabel terikat (Impulse Buying). Hasil uji t dapat dilihat pada tabel coefficients. Dari tabel 3 dapat dijelaskan bahwa:

1. Hasil nilai signifikansi variabel personal selling sebesar $0,00<0,05$ maka hipotesis diterima, yang berarti bahwa personal selling berpengaruh secara signifikan terhadap impulse buying konsumen produk Oriflame di Kota Langsa. Hal ini dikarenakan konsumen lebih menyukai peran sales/member Oriflame dalam melakukan personal selling dengan melakukan konsultasi dan pemberian contoh Produk secara langsung pada konsumen yang membuat konsumen menarik melakukan impulse buying. Hasil penelitian ini sama dengan penelitian dengan Pradhana dan Martini (2018) dan Sari dan Widad dan Rosa (2019) yang menyatakan bahwa personal selling berpengaruh signifikan terhadap impulse buying.

2. Hasil nilai signifikansi price discount sebesar $0,018<0,05$ maka hipotesis diterima, yang berarti bahwa price discount berpengaruh secara signifikan terhadap impulse buying konsumen produk Oriflame di Kota Langsa. Hal ini dikarenakan konsumen produk Oriflame memiliki ketertarikan terhadap price discount yang diberikan oleh Oriflame yang berbeda setiap bulannya dan potongan harga pada hari-hari tertentu untuk memikat konsumen melakukan impulse buying. Hasil penelitian ini sama dengan penelitian Pradhana dan Martini (2019) dan Syazkia dan Yulianti 
(2018) yang mengatakan bahwa price discount berpengaruh signifikan terhadap impulse buying.

3. Hasil nilai siginifikan variabel bonus pack sebesar $0,00<0,05$ maka hipotesis diterima, yang berarti bahwa bonus pack berpengaruh secara signifikan terhadap impulse buying konsumen produk Oriflame di Kota Langsa. Hal ini dikarenakan tinggi ketertarikan konsumen mendapatkan barang yang lebih murah dengan cara membeli produk set atau bonus pack yang membuat konsumen melakukan impulse buying secara tidak langsung. Hasil penelitian ini sama dengan penelitian Safa'atillah (2017) dan Lestari (2018) yang menyatakan bahwa bonus pack berpengaruh signifikan terhadap impulse buying.

\section{Uji F}

Uji $F$ yaitu uji untuk mengetahui signifikansi pengaruh variabel bebas (personal selling, price discount, bonus pack) secara simultan ataupun bersama-sama menerangkan variabel terikat (impulse buying). Hasil uji $\mathrm{F}$ dapat dilihat pada tabel 5. Dari tabel 3 dapat diketahui nilai $F$ sig. Sebesar 0,000. Oleh karena itu nilai $\mathrm{F}$ sig $0,000<0,05$ maka dapat dinyatakan bahwa personal selling, price discount, dan bonus pack secara simultan berpengaruh sigmifikan terhadap impulse buying konsumen produk Oriflame di Kota Langsa.

Hal ini menggambarkan ketiga variabel secara simultan mempengaruhi konsumen dalam melakukan impulse buying karena perpaduan antara ketiga variabel tersebut dianggap penting dalam melakukan impulse buying. Hasil penelitian ini sama dengan penelitian Pradhana dan Martini (2018) menyatakan bahwa personal selling, price discount, bonus pack secara simultan berpengaruh signifikan terhadap impulse buying. Dengan demikian maka hipotesis dalam penelitian ini dapat diterima.

Tabel 5. ANOVA

\begin{tabular}{|c|c|c|c|c|c|}
\hline Model & Sum of Squares & Df & Mean Square & $\mathrm{F}$ & Sig. \\
\hline 1. Regression & 721.722 & 3 & 240.574 & 49.905 & $.000_{\mathrm{a}}$ \\
\hline Residual & 448.319 & 93 & 4.821 & & \\
\hline Total & 1170.041 & 96 & & & \\
\hline
\end{tabular}

a. Predictors: (constan), Bonus Pack, Price Dicount, Personal Selling

b. Dependent Variabel: Impulse Buying

Sumber: data primer, diolah (2019)

\section{KESIMPULAN DAN SARAN}

Setelah dilakukan pengujian, hasil penelitian dan pembahasan maka dapat disimpulkan bahwa Personal Selling, Price Discount dan Bonus Pack berpengaruh signifikan terhadap Impulse Buying konsumen produk Oriflame di Kota Langsa. Hasil penelitian yang dilakukan terhadap uji $\mathrm{F}$ menunjukkan bahwa Personal Selling, Price Discount dan Bonus Pack secara simultan berpengaruh signifikan terhadap Impulse Buying konsumen produk Oriflame di Kota Langsa
Berdasarkan hasil penelitian, maka dapat disarankan bahwa Perusahaan Oriflame dapat membuat traning-traning kepada para member dalam mempelajari produk-produk yang telah tersedia. Agar para member dapat menjelaskan dengan baik kegunaan dari produk Orifame. Perusahaan juga dapat memberikan potongan harga pada hari-hari besar seperti Idul Adha, Idul Fitri, Natal dengan flash salei dalam jangka waktu 24 jam. Pemberian bazar juga harus dengan stok barang yang cukup, agar tidak membuat konsumen kecewa. Selanjutnya Perusahaan lebih memperhatikan bonus pack yang lebih menarik dari segi harga maupun ukuran produk agar manfaat produk dapat 
dirasakan oleh konsumen. Perusahaan juga harus memperhatikan tampilan produk dengan desain yang unik dan menarik, sehingga konsumen langsung tertarik untuk membelinya. Untuk penelitian selanjutnya dapat menggunakan variabel/dimensi lain seperti Brand Image, Kualitas Produk dan Promosi.

\section{REFERENSI}

Akkas, N. 2016. Pengaruh Komunikasi Pemasaran Terpadu terhadap Citra Perusahaan dan Dampaknya terhadap Kepuasa Pelanggan Membeli Mobil pada PT. Hadji Kalla Cabang Palu. e-Jurnal Katalogis, Vol. 4, No. 1, Hal.2436

Ardianto, Jony. 2015. 177 Problem Solving of Direct Marketing. Yogyakarta: Flashbooks.

Artana, I Putu Widya dkk. 2019. Pengaruh Store Atmosphere, Display Product, dan Price Discount terhadap Impulse Buying (Studi kasus pada Indomaret di Kota Denpasar). E-Jurnal Ekonomi Dan Bisnis Universitas Udaya. Vol.8 No.4 Hal.369-394.

Bayley, G. \& Nancarrow, C. 1998. Impulse Purchasing: a Qualitative Exploration of the Phenomenon. Qualitative Market Research: An International Journal, Vol.1 No.2.

Belch, G.E\& Belch, M.A. 2009. Advertising and Promotion: An Integrated Marketing Communication Perspective. Ninth Edition. New York: McGraw Hill.

Bujangga, Putu Hendra dan Hidaya, Rahmat. 2019. Pengaruh Personal Selling dan Fitur Iklan melalui Media Social terhadap Keputusan Pembelian produk Indihome (Strudi Kasus pada PT. Telkom Turangga Bandung Tahun 2018). E-Jurnal Procceding of Apply Science. Vol.5 No.1 Hal.74-81.

Clow, K. E., \& Baack, D. E. 2012. Integrated Advertising, Promotion and Marketing Communications. Prentice Hall PTR

Dewi, Liliana dan Magdalena, Felicia. 2017. Pengaruh Personal Selling dan Word of
Mouth terhadap Brand Awareness Bisnis Mahasiswa Universitas Ciputra. Jurnal Eksekutif. Vol.14 No.2 Hal.253-261.

Gumilang, Wayan Aris Dan Nurcahya, I Ketut. 2016. Pengaruh Price Discount Dan Store Atmosphere Terhadap Emotional Shopping Dan Impulse Buying. EJurnal Manajemen Unud. Vol.15, No.3. Hal.1859-1888.

Jeffrey dan Wijaya, Melly.2019. Pengaruh Kualitas Produk dan Personal Selling terhadap Keputusan Pembelian Mobil Agya pada PT. Astra International TbkTso Medan Gatsu Branch. Jurnal Manajemen. Vol.5 No.2 Hal.153-160.

Kotler, Philip dan Keller, Kevin Lane. 2012. Manajemen Pemasaran. Edisi 12. Jakarta: Erlangga dan Armstrong, Gary. 2014. Manajemen Pemasaran. Jakarta: Erlangga.

Kurniawan, Denny dan Kunto, Yohanes Sanding. 2013. Pengaruh Promosi dan Store Atmosphere terhadap Impulse Buying dengan Shopping Emotion Sebagai Variabel Intervening Studi Kasus di Matahari Department Store Cabang Supermall Surabay. Jurnal Manajemen Pemasaran Petra. Vol.1 No.2 , Hal. 1-8

Kwan, Oky Gunawan. 2016. Pengaruh Sales Promotion dan Store Atmosphere terhadap Impulse Buying dengan Positive Emotion sebagai Variabel Intervening pada Planet Sports Tunjungan Plaza Surabaya. Jurnal Manajemen Pemasaran. Vol.10 No.1 Hal. 27-34.

Mowen, J.C. and Minor, M., 2002. Perilaku konsumen. Alih Bahasa Lina Salim, Edisi Kelima. Jakarta: PT. Erlangga.

Nasib. 2017. Pengaruh Price Discount dan Bonus Pack terhadap Keputusan Impulse Buying Pada PT. Toyota Auto 2000 Cabang Sisingamangraja Medan, Journal Of Business Studies. Vol.2 No.2 Hal.30-50. 
Prihastama, Brian Vicky. 2016. Pengaruh Price Discount dan Bonus Pack terhadap Impulse Buying pada Pelanggan Minimarket (Studi pada Pelanggan Minimarket Indomaret Jl. Demangan Baru, Depok,Sleman, Yogyakarta). Skripsi. Universitas Negeri Yogyakarta. Yogyakarta.

Rochman, Fajar Nur. 2016. Pengaruh Price Discount, Bonus Pack, dan In-Store Display terhadap Impulse Buying (Studi pada Giant Supermarket Yogyakarta). Skripsi. Universitas Muhammadiyah Purworejo. Purworejo.

Rofidi, Moch Arkhan Nur. 2017. Pengaruh Price Discount, Bonus Pack dan Pelayanan terhadap Peningkatan Impulse Buying pada Toko Bangunan UD Aryan Kec. Plemahan Kab. Kediri. Jurnal Simki-Economic. Vol.01 No.03 Hal.116.

Safa'atillah, Nurus. 2017. Analisis Pengaruh Faktor Price Discount, Bonus Pack dan Brand Image terhadap Konsumen dalam Melakukan Impulse Buying pada Produk Oriflame di Kota Lamongan. Jurnal Penelitian Ilmu Manajemen. Vol.2 No.3 Hal.483-493.

Sari, Apria. Widad dan Rosa, Aslamia. 2015. Pengaruh Sales Promotion, Personal Selling, dan Visual Merchandising terhadap Perilaku Impulse Buying Konsumen Matahari Departemen Store PsX Palembang. Jurnal Jembatan. Vol.12 No.1 Hal.45-56.

Sari, Aprilia Eka. 2014. Analisis Faktor yang Mempengaruhi Pembelian Spontan. Jurnal Sains Pemasaran Indonesia. Vol.13 No.1 Hal.55-73.

Sari, Della Ruslimah dan Faisal, Ikhwan. 2018. Pengaruh Price Discount, Bonus Pack, dan In-Store Disply terhadap Keputusan Impulse Buying pada Giant Ektra Banjar. Jurnal Sains Manajemen dan Kewirausahaan. Vol.2 No.1 Hal.51-60. Sarwono, Jonathan. 2010. Metode Riset

Skripsi Pendekatan Kuantitatif. Media Elek Komputindo. Jakarta.

Schiffman, L.G. and Kanuk, L.L., 2007. Purchasing Behavior. Upper Saddle River, NJ: Pearson Prentice Hall

Sinulingga, Sukaria.2013. Metode Penelitian. Medan.USU Press.

Sriwidodo, Untung dan Sumaryanto. 2017. Analisis Faktor-Faktor Berpengaruh terhadap Perencanaan Investasi (Survei Masyarakat Berpenghasilan Tetap Desa Jaten Kab. Karanganyar). E-Jurnal Unisri. Vol.1 No.1 Hal.9197.

Sugiyono. 2017. Metode Penelitian Kuantitatif Kualitatif dan R \& D. Bandung: Alfabeta.

Sunyoto, Danang. 2011. Metode Penelitian Untuk Ekonomi. Jakarta: Caps.

Syazkia, Sindy Nur dan Yuliati, Ai Lili. 2018. Pengaruh Bonus Pack dan Price Discount terhadap Impulse Buying pada Konsumen PT Lion Super Indo Gerai Antapani. E-Jurnal Proceeding of Management. Vol.5 No.2 Hal.25612568.

Wahyudi, Septian. 2017. Pengaruh Price Discount terhadap Impulse Buying. Jurnal Valuta, Vol.3 No.2

Zahari. 2018. Analisis Pengaruh Sponsorship, Personal Selling dan Pricing Strategy terhadap Costumer Engagement Serta Dampaknya pada Custumer Retention. Tesis. Universitas Syiah Kuala. Banda Aceh. 